\title{
A Comparative Study of Pricing Option with Efficient Methods
}

\author{
Sujon Chandra Sutradhar and A B M Shahadat Hossain
}

\begin{abstract}
Our main objective of this paper is to introduce four individual techniques of pricing options; the techniques are Binomial method, Trinomial method, Monte Carlo simulation and Black-ScholesMerton model. Because they play a significant role in option valuation of stock price dynamics, risk managements as well as stock market. In this paper, we briefly discuss all these four methods with their properties and behavior. We also focused on numerical technique for the higher accuracy of option pricing and compare them graphically. We use the Computer Algebra System (CAS) Python (Edition 2019.3.1) for this purpose.
\end{abstract}

Index Terms - Binomial method, Trinomial method, Monte Carlo simulation, Black-Scholes-Merton model.

\section{INTRODUCTION}

$\mathrm{P}$ RICING option is very popular now a day and many scholars have attracted to work in valuing option by using of the tree methods. Black and Scholes (1973) introduced the well-known pricing option model. As the intelligence of mathematics and analysis behind this model is very deep and critical to realize and that is the reason is not well known by the universal readers. Merton published a renowned paper named 'Theory of rational option pricing'. There gained a great achievement and makes a great breakthrough in the area of option pricing when they introduced the model named 'BLS formula or Black Scholes Merton.' Later Cox et al. introduced a binomial option-valuation model which is widely realized and easy to assent due to its momentary mathematical methods and the imbedded economic significance. So, it is broadly used in the financial market. This model is very much simple and allows only two possible paths in a certain time interval. The underlying stocks can go upward and go downward as well with a probability. Though it is easy

DOI: https://doi.org/10.3329/gubjse.v7i0.54024

This paper was received on 16 December 2020, revised on 14 February 2021 and accepted on 19 April 2021.

Sujon Chandra Sutradhar is with the Department of Applied Mathematics, University of Dhaka, Dhaka, Bangladesh.

E-mail: sujonchandra-2014916205@amath.du.ac.bd

A B M Shahadat Hossain is with the Department of Applied Mathematics, University of Dhaka, Dhaka, Bangladesh. E-mail:abmsh@du.ac.bd to use, it has some drawback also. It could lead major error in the calculations especially when the option is more complex. So it should not be the right choice for more complicated options. Then an amazing Trinomial option pricing model was introduced by Boyle. [1] Later it was modified and well solved by Boyle with Lau, Kamrad and Ritchen. They have proposed that there are three different paths for the underlying assets which is up, equal and down for each time interval with a certain probability. It is more realistic than the binomial option pricing and can used in the more complicated options. It is now widely used in different fields of finance.

Later Han developed trinomial tree model. $\mathrm{He}$ developed an efficient way of valuing option numerically and described the results for continuous distribution of underlying stock price movements and found more accurate results compared to the binomial option pricing model.

In the field of finance, Monte Carlo option pricing model is very much popular now a day. In an MC option model, Monte Carlo approaches is used to compute the value of an option with multiple sources of improbability or with complicated features. In 1977, Phelim Boyle first introduce the Monte Carlo model for pricing European options. In 1996, M. Broadie and P. Glasserman worked on pricing Asian option using Monte Carlo simulation. An important development of Monte Carlo methods for options early exercise features were introduced in 1996 by Carriere.

Our focus in this paper is to price option by using binomial and trinomial option pricing method. For practical view, we use the market data so that we can predict the market volatility from the previous data, which is known as the historical volatility. We work for both European and American call option pricing. We also compare the option value with the exact solution BLS option-pricing model and MC option pricing method for the European option. Again, we also discuss the dividend effect for option pricing and show the results in graphical representation

\section{Methodology}

\section{A. Option}

Options are derivatives, which are dealt both on exchanges and in the over-the-counter market. It is 
contract that gives rights to the holder but not obligation. There are mainly two categories of options.

- Call option

- Put option

Call is one type of these options which gives its holder the right but not the obligation to buy an underlying asset in a specific price on a specific date. Similarly put is another type of option that gives right but not obligation to its owner to sell an underlying asset in a specific price on a specific date. The predetermined price and date are known as strike price $(\mathrm{K})$ and expiration date $(\mathrm{T})$ respectively. If the option is exercised before the expiration date then it is American option [2] otherwise if the option is exercised only on the expiration date then it is the European option. Let $S_{T}$ be the final price and $K$ be the strike price of the underlying asset. Let us consider that the option costs nothing.

In a call option, payoff from long position is, $\max \left(S_{T}-K, 0\right)$. This replicates that if $S_{T}>K$ the option will be exercised and will not be exercised if $S_{T} \leq K$. The payoff to its holder from a long position in a put option is $\max \left(K-S_{T}, 0\right)$. The Payoff from short position in a call option is,

$-\max \left(S_{T}-K, 0\right)=\min \left(K-S_{T}, 0\right)$

In a long positioned put option the payoff for its holder is $\max \left(K-S_{T}, 0\right)$

In European option, we can only exercise our option on the expiration date but in American type option, we can exercise it before the determined date, because of it, this type of option is more costly than the previous type.

\section{B. Binomial option pricing model (BOPM)}

In BOPM the whole time frame divided into small interval of size $\delta t$. It confirms us that in each time period the stock price moves either up $S u$ and down $S d$ from its initial value $S$. In fig. 1 we have showed a two steps binomial tree.

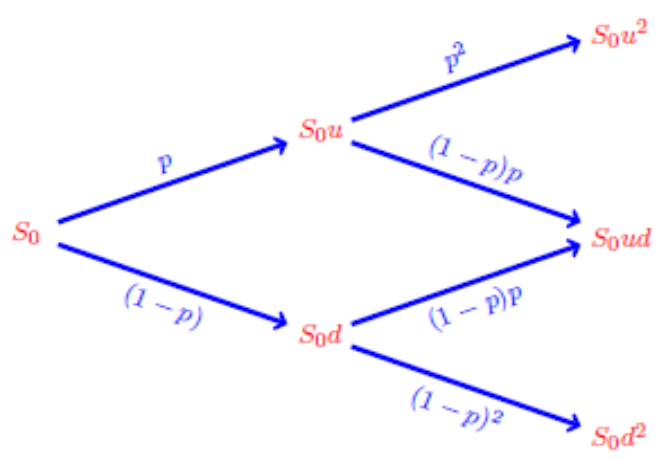

Where $u>1$ and $d<1$. The movement from $S$ to $S u$ is called the up movement and $S d$ is called the down movement. The probability for the up movement as well as for the down movement is $p$ and $(1-p)$ respectively. During the time interval $\delta t$, the parameters $p, u, d$ must give the correct value for the mean and the variance. The expected return from an asset in the risk neutral world is the risk-free interest rate and it is denoted by $r$. When there is yield of $q$, then the expected return from the underlying asset will be $(r-q)$. This means that the expected value after certain time interval of size $\delta t$ must be $S e^{(r-q) \delta t}$. [3] If we match the mean return with the above mentioned tree, we get the following relationship

$$
\begin{aligned}
& S e^{(r-q) \delta t}=p S u+(1-p) S d \\
& \Rightarrow e^{(r-q) \delta t}=p u+(1-p) d
\end{aligned}
$$

The variance of a variable $x$ is defined by $E\left(x^{2}\right)-[E(x)]^{2}$. Now let us define $R$ is the percentage change of the asset price at time $\delta t$, there is probability $p$ that $(1+R)$ is $u$ and a probability $(1-p)$ is $\mathrm{d}$, then the variance of $(1+R)$ is $p u^{2}+(1-p) d^{2}-e^{2(r-q) \delta t}$. The variance of $(1+R)$ is the same as the variance of $R$ and this is $\sigma^{2} \delta t$.

So $p u^{2}+(1-p) d^{2}-e^{2(r-q) \delta t}=\sigma^{2} \delta t$

From equation (1)

$e^{(r-q) \delta t}(u+d)=p u^{2}+(1-p) d^{2}+u d$ so

$e^{(r-q) \delta t}(u+d)-u d-e^{2(r-q) \delta t}=\sigma^{2} \delta t$

A last but not least condition applied by CRR (1979) consider $u d=1$, and by solving the above equation we can find the relation, [4]

$p=\frac{a-d}{u-d}, u=e^{\sigma \sqrt{\delta t}}, d=e^{-\sigma \sqrt{\delta t}}, a=e^{(r-q) \delta t}$

\section{Expressing the approach algebraically}

Assume the life of the option is partitioned into $n$ subinterval of length $\delta t$. We will mention to the $j^{\text {th }}$ node at time $i \delta t$ as the $(i, j)$ node, (where $0 \leq i \leq n$ and $0 \leq j \leq i)$. Define $f_{i, j}$ is the option value at the $(i, j)$ node. At the $(i, j)$ node the underlying asset is $S_{0} u^{i} d^{i-j}$. For a call option payoff

Fig. 1. Two steps binomial tree. 
from the underlying asset at time $T$ (at the maturity) is $\max \left(S_{T}-K, 0\right)$. So

$$
f_{n, j}=\max \left(S_{0} u^{i} d^{n-j}-K, 0\right) ; j=0,1, \ldots ., n
$$

Similarly, for a put option payoff at time $T$ is $\max \left(K-S_{T}, 0\right)$; so,

$$
f_{n, j}=\max \left(K-S_{0} u^{i} d^{n-j}, 0\right) ; j=0,1, \ldots ., n
$$

The probability of moving at time $i \delta t$ from node $(i, j)$ to the $(i+1, j+1)$ node at time $(i+1) \delta t$ is $p$, and similarly the probability of moving at time $i \delta t$ from node $(i, j)$ to the $(i+1, j)$ node at time $(i+1) \delta t$ is $(1-p)$. If early exercise is not allow, then risk neutral valuation gives

$$
f_{i, j}=e^{-r \delta t}\left[p f_{i+1, j+1}+(1-p) f_{i+1, j}\right]
$$

For $0 \leq i \leq n-1$ and $0 \leq j \leq i$. Now if we consider early exercise such as American option, then we should compare $f_{i, j}$ with the options intrinsic value, so, for a call option, [5]

$f_{i, j}=\max \left\{S_{0} u^{j} d^{i-j}-K, e^{-r \delta t}\left[p f_{i+1, j+1}+(1-p) f_{i+1, j}\right]\right\}$

And for put option,

$$
f_{i, j}=\max \left\{K-S_{0} u^{j} d^{i-j}, e^{-r \delta t}\left[p f_{i+1, j+1}+(1-p) f_{i+1, j}\right]\right\}
$$

\section{Trinomial option pricing model (TOPM)}

The calculating procedure of TOPM is as similar as the BOPM. Although it is more realistic. In trinomial tree, we observed three possibilities of the movement of share price (stock price) $S u, S d$ and $S$ from the initial stock price $S$. The probabilities of this movements are $p_{u}, p_{m}$ and $p_{d}$.

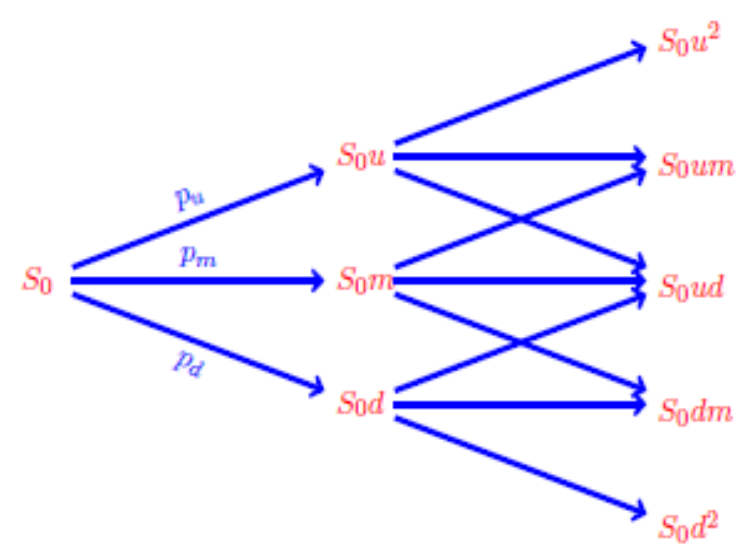

Fig.2. Two steps trinomial tree

In our model, if we claim stock price increases from step $(n-1)$ to step $n$, then the stock price at step $(n+1)$ is $u S_{n}, m S_{n}$ and $d S_{n}$ with the probability $p_{u}, p_{m}$ and $p_{d}$ respectively. We have showed simple two steps trinomial tree in the above fig. 2

In the risk neutral condition, the expected asset price after the first interval is $S_{0} e^{r \delta t}$ where $(\delta t=T / n)$; that is,

$$
\begin{aligned}
S_{0} e^{r \delta t} & =p_{u} S_{0} u+p_{m} S_{0} m+p_{d} S_{0} d \\
\Rightarrow e^{r \delta t} & =u p_{u}+m p_{m}+d p_{d}
\end{aligned}
$$

Another two conditions come from the variance and property of probabilities;

$$
\begin{gathered}
u^{2} p_{u}+m^{2} p_{m}+d^{2} p_{d}-\left(e^{r \delta t}\right)^{2}=\sigma^{2} \delta t \\
p_{u}+p_{m}+p_{d}=1
\end{gathered}
$$

By solving the above equations (4), (5), and (6) we find the probabilities;

$$
\begin{aligned}
& p_{u}=\left(\frac{e^{r \delta t / 2}-e^{-\sigma \sqrt{\delta t / 2}}}{e^{\sigma \sqrt{\delta t / 2}}-e^{-\sigma \sqrt{\delta t / 2}}}\right) ; p_{d}=\left(\frac{e^{\sigma \sqrt{\delta t / 2}}-e^{r \delta t / 2}}{e^{\sigma \sqrt{\delta t / 2}}-e^{-\sigma \sqrt{\delta t / 2}}}\right) \\
& p_{m}=1-p_{u}-p_{d}
\end{aligned}
$$

Where, $u=e^{\sigma \sqrt{2 \delta t}}, d=e^{-\sigma \sqrt{2 \delta t}}$ and $m=1$.

The methodology of pricing option using a trinomial tree (TT) is same as the binomial tree (BT), once the share price tree is built and the option payoff at maturity time $T$ are calculated. For the call option $\max \left(S_{T}-K, 0\right)$ and for the put option $\max \left(K-S_{T}, 0\right)$. After that it remains to apply the following backward induction algorithm, where $i$ represents the time position and the $j$ represents the space position, then

$$
C_{i, j}=e^{-r \delta t}\left[p_{u} C_{i+1, j+1}+p_{m} C_{i+1, j}+p_{d} C_{i+1, j+1}\right]
$$

Now if the option is the American type then the option can be exercised before the expiry date $(T)$ with the same strike price, then the backward recursion takes the following form; [6]

For call:

$C_{i, j}=\max \left(S_{i, j}-K, e^{-r \delta t}\left[p_{u} C_{i+1, j+1}+p_{m} C_{i+1, j}+p_{d} C_{i+1, j+1}\right]\right)$

For put:

$C_{i, j}=\max \left(K-S_{i, j}, e^{-r \delta t}\left[p_{u} C_{i+1, j+1}+p_{m} C_{i+1, j}+p_{d} C_{i+1, j+1}\right]\right)$

\section{E. Monte Carlo Simulation}

The stochastic differential equation with drift term $\mu$ and diffusion term $\sigma$ is $d S_{t}=\mu S_{t} d t+\sigma S_{t} d W_{t}$ where, $W_{t}$ is a standard Brownian process. Now if the 
drift and diffusion are correlated with both $S$ and $t$ then discrete approximation is $\Delta S=\mu S \delta t+\sigma S \varepsilon \Delta W$ where $\varepsilon \sim \mathcal{N}(0,1)$. Now using Itô's lemma $d \ln \left(S_{t}\right)=\left(\mu-\sigma^{2} / 2\right) d t+\sigma d W_{t}$. Here $\ln \left(S_{t}\right)$ follows a standardized wiener process with constant mean and variance. This means that the change of $\ln \left(S_{t}\right)$ within time interval $\delta t$ is normally distributed. [7] i.e

$\ln \left(S_{t+\delta t}\right)-\ln \left(S_{t}\right) \sim \mathcal{N}\left[\left(\mu-\frac{\sigma^{2}}{2}\right) \delta t, \sigma^{2} \delta t\right]$

or, $\ln \left(S_{t+\delta t}\right) \sim \mathcal{N}\left[\ln \left(S_{t}\right)+\left(\mu-\frac{\sigma^{2}}{2}\right) \delta t, \sigma^{2} \delta t\right]$

$\ln \left(S_{t+\delta t}\right)-\ln \left(S_{t}\right)=\left(\mu-\frac{\sigma^{2}}{2}\right) \delta t+\sigma \varepsilon \sqrt{\delta t}$

or, $S_{t+\delta t}=S_{t} \exp \left[\left(\mu-\frac{\sigma^{2}}{2}\right) \delta t+\sigma \varepsilon \sqrt{\delta t}\right]$

If $t=0$, and $\delta t=T$, the equation moves to

$S_{T}=S_{0} \exp \left[\left(\mu-\frac{\sigma^{2}}{2}\right) \delta t+\sigma \varepsilon \sqrt{\delta t}\right]$

MC simulation is broadly used in for the commodity pricing where the payoff depends on the previous prices of the underlying commodities. In order to price the option first we need to divide the maturity time $T$ of options into $n$ subintervals with length $\delta t$, then by using the equation (7) sample the possible random path for the stock price and get the stock price $S_{T}$ at the maturity date. After collecting all the payoffs, discount the average payoff we get the expected results, which is

For call: $e^{-r T}\left(\frac{1}{n} \sum_{i=1}^{n} \max \left(S_{T}-K, 0\right)\right)$

For put: $e^{-r T}\left(\frac{1}{n} \sum_{i=1}^{n} \max \left(K-S_{T}, 0\right)\right)$

\section{F. Black-Scholes Merton pricing formula}

If the option value $f$, risk neutral interest rate $r$ ,market annual volatility $\sigma$ and the stock price $S$ then from the solution of BLS-Merton differential equation, [8][9]

$$
\frac{\partial f}{\partial t}+r f \frac{\partial f}{\partial S}+\frac{1}{2} \sigma^{2} S^{2} \frac{\partial^{2} f}{\partial S^{2}}=r f
$$

Prices of the European call and put options form are

$C=S_{0} N\left(d_{1}\right)-K e^{-r T} N\left(d_{2}\right)$

$$
P=K e^{-r T} N\left(-d_{2}\right)-S_{0} N\left(-d_{1}\right)
$$

Where $\quad d_{1}=\frac{\ln \left(S_{0} / K\right)+\left(r+\sigma^{2} / 2\right)(T-t)}{\sigma \sqrt{T-t}}$

$$
d_{2}=\frac{\ln \left(S_{\mathrm{o}} / K\right)+\left(r-\sigma^{2} / 2\right)(T-t)}{\sigma \sqrt{T-t}} ;
$$

The formula $N(x)$ is the CDF for a standard normal distribution with mean 0 and variance 1. [10]

\section{RESULT}

TABLE I

\begin{tabular}{|c|c|c|c|}
\hline Variable & Value & $\begin{array}{c}\text { Binomial } \\
\text { Tree }\end{array}$ & $\begin{array}{c}\text { Trinomial } \\
\text { Tree }\end{array}$ \\
\hline $\begin{array}{c}\text { Interest } \\
\text { Rate }\end{array}$ & $\begin{array}{l}0.01 \\
0.02 \\
\\
0.03 \\
0.04 \\
0.05\end{array}$ & $\begin{array}{l}155.5790 \\
158.3135 \\
161.0505 \\
163.7898 \\
166.5308\end{array}$ & $\begin{array}{l}155.3498 \\
158.0743 \\
160.8033 \\
163.5365 \\
166.2733\end{array}$ \\
\hline $\begin{array}{c}\text { Volatility } \\
(\%)\end{array}$ & $\begin{array}{l}23 \\
25 \\
30\end{array}$ & $\begin{array}{l}150.6632 \\
151.3778 \\
155.5790 \\
158.4847 \\
165.7912\end{array}$ & $\begin{array}{l}151.2171 \\
152.3539 \\
155.3499 \\
158.0472 \\
164.8304\end{array}$ \\
\hline $\begin{array}{l}\text { Strike } \\
\text { Price }\end{array}$ & $\begin{array}{l}785 \\
900 \\
\\
800 \\
700 \\
750\end{array}$ & $\begin{array}{l}143.6316 \\
234.2008 \\
186.1183\end{array}$ & $\begin{array}{c}155.3498 \\
72.5624 \\
143.1555 \\
233.9966 \\
186.8503\end{array}$ \\
\hline $\begin{array}{c}\text { Maturity } \\
\text { Time }\end{array}$ & $\begin{array}{c}100 \\
200 \\
\\
300 \\
400 \\
50\end{array}$ & $\begin{array}{l}184.6971 \\
195.6898 \\
148.5626\end{array}$ & $\begin{array}{l}155.3498 \\
170.6728 \\
182.7576 \\
195.3513 \\
148.7628\end{array}$ \\
\hline
\end{tabular}

AMERICAN CALL OPTION PRICING UNDER TWO DIFFERENT METHODS 
TABLE II

EUROPEAN CALL OPTION PRICES UNDER DIFFERENT METHODS

\begin{tabular}{|c|c|c|c|c|c|}
\hline Variable & Value & $\begin{array}{c}\text { BT } \\
\text { Model }\end{array}$ & TT Model & $\begin{array}{c}\text { Black } \\
\text { Scholes }\end{array}$ & $\begin{array}{l}\text { Monte } \\
\text { Carlo }\end{array}$ \\
\hline $\begin{array}{l}\text { Number } \\
\text { of steps }\end{array}$ & \begin{tabular}{|c|}
\multicolumn{1}{c|}{} \\
10 \\
\\
100 \\
1000 \\
5000
\end{tabular} & $\begin{array}{l}155.5790 \\
155.3499 \\
155.4879 \\
155.5192 \\
155.5166\end{array}$ & $\begin{array}{l}155.5161 \\
155.6727 \\
155.5219 \\
155.5160 \\
155.5161\end{array}$ & $\begin{array}{l}155.5160 \\
155.5161 \\
155.5160 \\
155.5160 \\
155.5160\end{array}$ & $\begin{array}{c}97.5437 \\
195.1493 \\
119.3861 \\
155.3216 \\
153.3974\end{array}$ \\
\hline $\begin{array}{c}\text { Interest } \\
\text { Rate }\end{array}$ & $\begin{array}{c}0.01 \\
0.02 \\
0.03 \\
0.05 \\
0.1\end{array}$ & $\begin{array}{l}161.0505 \\
166.5308 \\
180.2500\end{array}$ & $\begin{array}{l}155.5161 \\
158.0743 \\
160.8034 \\
166.2733 \\
179.9936\end{array}$ & $\begin{array}{l}155.5160 \\
158.2202 \\
160.9311 \\
166.3700 \\
180.0392\end{array}$ & $\begin{array}{l}153.3974 \\
155.9964 \\
157.5958 \\
164.2374 \\
178.0168\end{array}$ \\
\hline Volatility & $\begin{array}{l}23 \% \\
30 \% \\
35 \% \\
20 \% \\
15 \%\end{array}$ & $\begin{array}{l}155.5790 \\
165.7912 \\
173.1325 \\
151.3778 \\
149.6079\end{array}$ & $\begin{array}{l}155.5161 \\
164.8304 \\
171.6475 \\
152.3579 \\
149.5380\end{array}$ & $\begin{array}{l}155.5160 \\
164.1484 \\
171.5658 \\
152.7103 \\
149.6437\end{array}$ & $\begin{array}{l}153.3974 \\
162.6272 \\
169.9201 \\
150.5558 \\
146.6667\end{array}$ \\
\hline $\begin{array}{l}\text { Strike } \\
\text { Price }\end{array}$ & $\begin{array}{l}785 \\
900 \\
\\
800 \\
700 \\
750\end{array}$ & $\begin{array}{l}143.6316 \\
234.2008 \\
186.1183\end{array}$ & $\begin{array}{c}155.5161 \\
72.5624 \\
143.1555 \\
233.9966 \\
186.8503\end{array}$ & $\begin{array}{c}155.5160 \\
71.5205 \\
\\
142.7277 \\
234.2826 \\
186.87851\end{array}$ & $\begin{array}{c}153.3974 \\
69.6888 \\
140.4281 \\
232.4011 \\
184.0479\end{array}$ \\
\hline $\begin{array}{l}\text { Maturity } \\
\text { Time }\end{array}$ & $\begin{array}{c}300 \\
400 \\
50\end{array}$ & $\begin{array}{l}184.6971 \\
195.6898 \\
148.5626\end{array}$ & $\begin{array}{l}182.7576 \\
195.3513 \\
148.7628\end{array}$ & $\begin{array}{l}183.8515 \\
196.3507 \\
148.7374\end{array}$ & $\begin{array}{l}153.3974 \\
169.2282 \\
181.1051 \\
196.4881 \\
145.8121\end{array}$ \\
\hline
\end{tabular}

In this paper, we use the daily data of Google (NASDAQ. GOOG) from 2015-01' to '2017-07' and find the historical volatility $23 \%$, we consider the initial stock price $\$ 930.5$, risk free interest rate $1 \%$ and 100 days maturity times, we consider the 252 trading days and zero dividend yield here. The results from the American call option is in table 1, and European call option price is in table 2

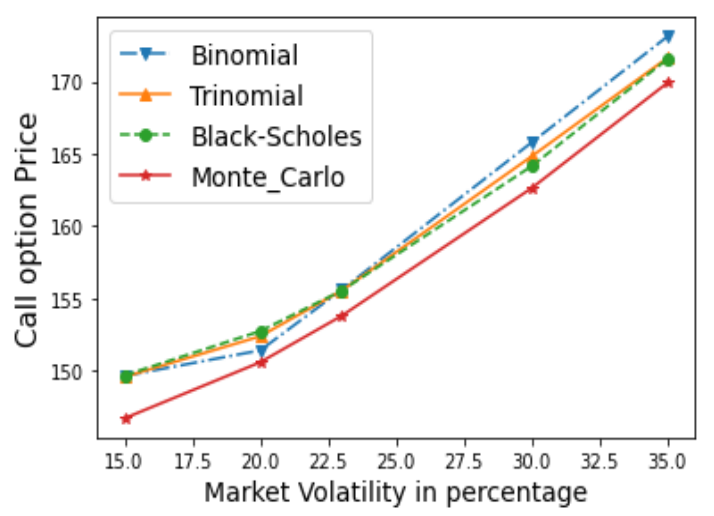

(a) Call price against volatility

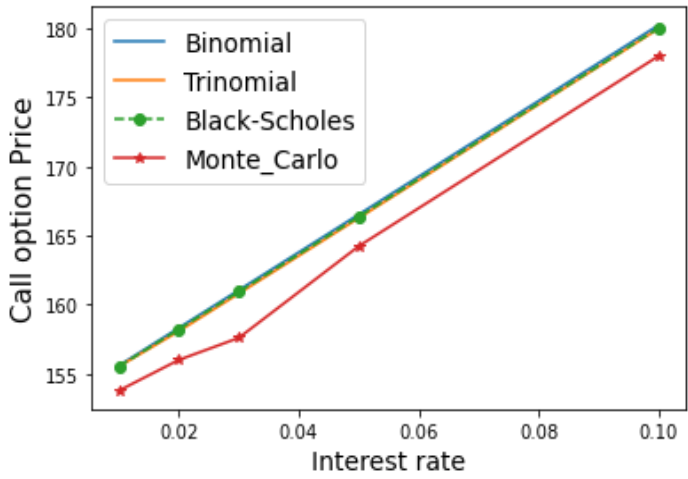

(b) Call price against interest rate

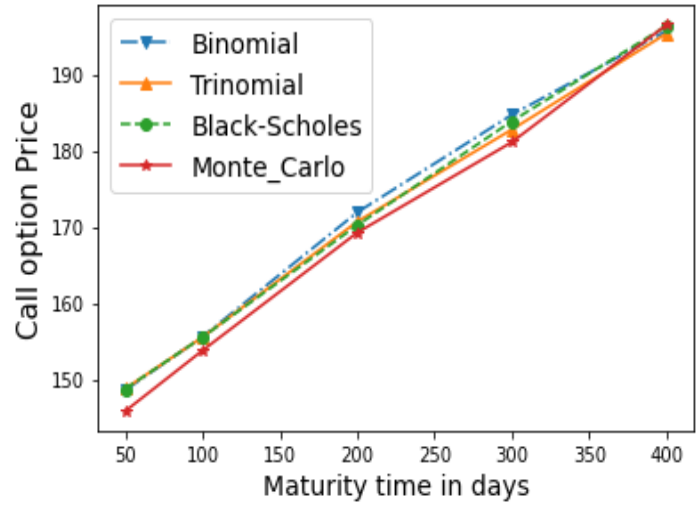

(c) Call price against maturity time

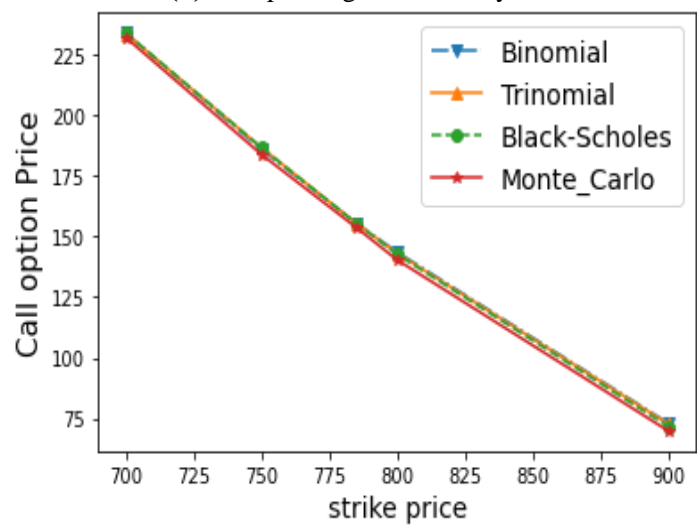

(d) Call price against strike price

Fig. 3. European call option pricing under different volatility, interest rate, maturity, and strike price 


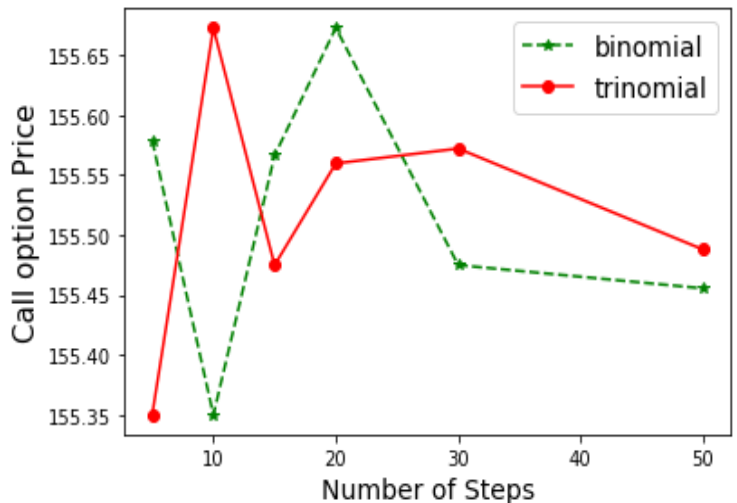

(a) Call price against number of steps

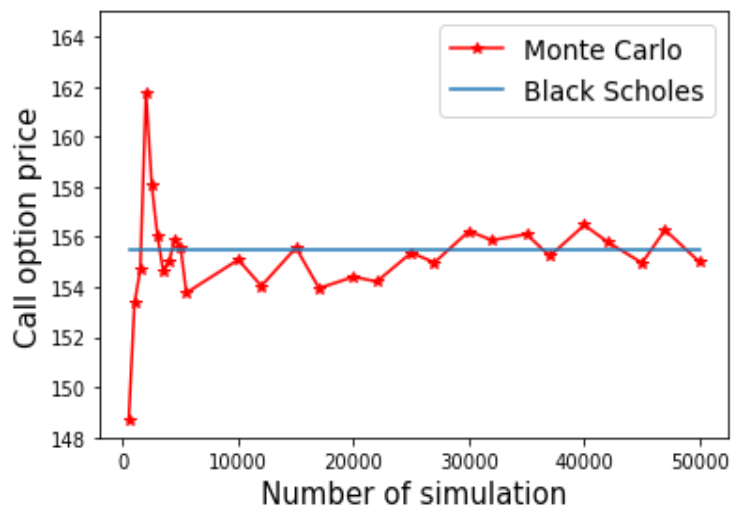

(b) Call price under Monte Carlo simulation

Fig. 4. European call Option Pricing under different step size and Monte Carlo simulation

In Fig. 3, we tried to show how the behavior of European call option value changes under different factors as volatility, interest rate, expiration time and strike prices with four different methods as binomial, trinomial, Monte Carlo and Black-Scholes model. In fig. 3(a). we see that the call option price increases with volatility. The four-mentioned methods almost give the same solution but trinomial method gives the result more similar to the exact solution, Black-Scholes model. In fig. 3(b). it is clear that call price increases with the interest rate. In this case, Monte Carlo simulation gives us a little fluctuating result than the others. In fig. 3(c). it is evident that call price increases with the increases of maturity time almost linearly. In fig. 3(d). it is obvious that call price decreases if we increase the strike price. In this case, we see that all the methods give almost exact result.

In Fig. 4, we tried to show how call option prices differ with the step sizes in both binomial and trinomial tree methods and how Monte Carlo simulation converges with Black-Scholes option prices by increasing number of simulations. In fig. 4(a). we find that, both binomial and trinomial tree give us almost same results with the increasing step sizes and in fig. 4(b) we established that if we increase the number of simulations Monte Carlo method converges the exact solution more quickly.

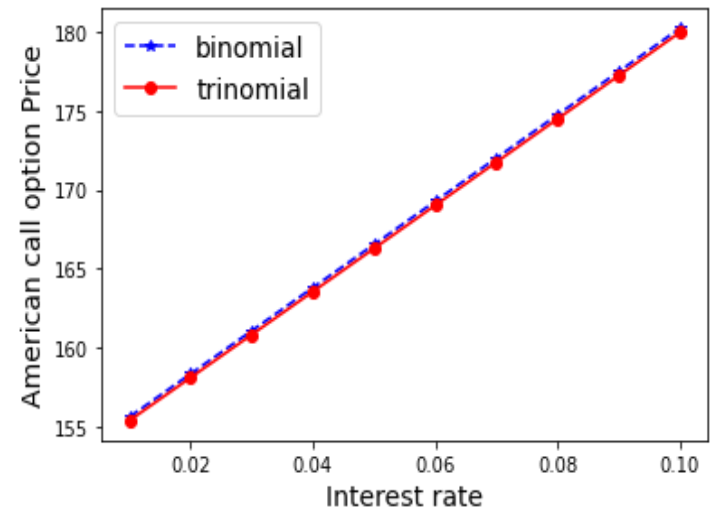

(a) American Call price against interest rate

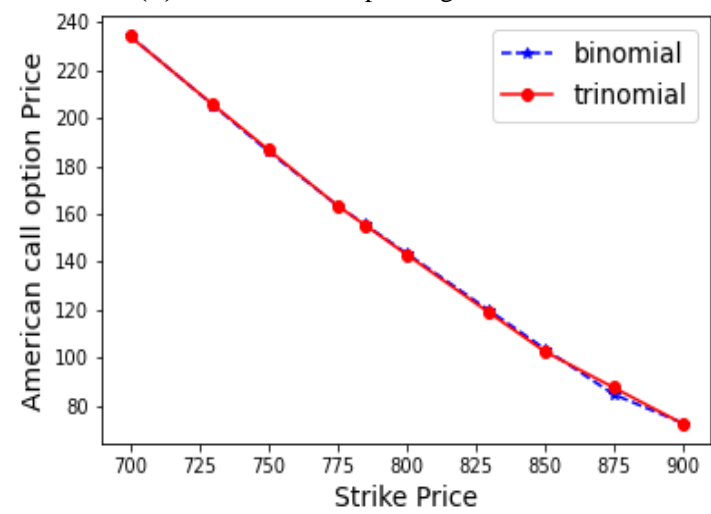

(b) American Call price against strike price

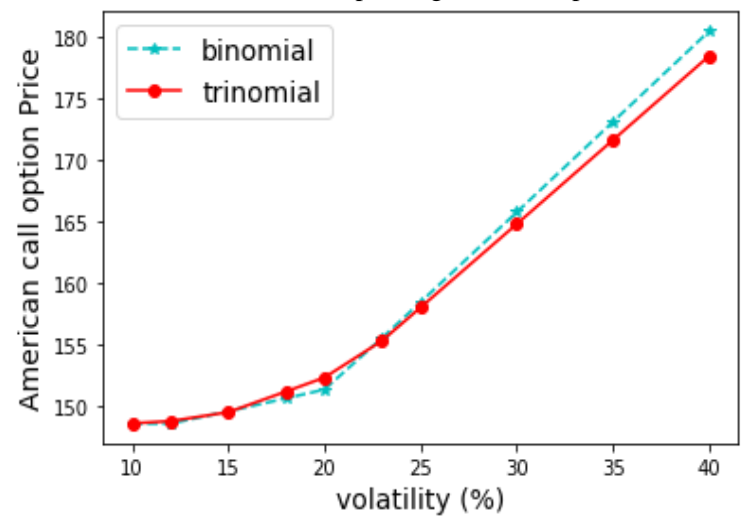

(c) American Call price against volatility

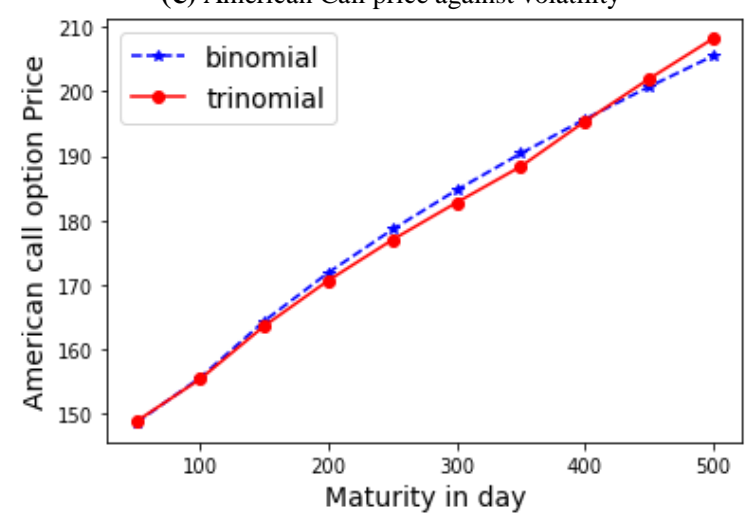

(d) American Call price against maturity in day

Fig. 5. American Call options under binomial and trinomial methods. 
Now it is time to discuss the option when it is the American type, and in Fig. 5, we show how call option prices differ with some essential factors as interest rates, strike prices, volatility and time to maturity under two essential option pricing methods such as binomial and trinomial tree method. In fig. 5(a). we can raise our opinion as by increasing interest rate, we can increase option value. In both methods, we almost get the same result. In fig. 5(b), it is clear that if we increase strike price, then option price decreases and both methods give the same result. Similarly, In fig. 5(c). we found that if the volatility increases or the market is more volatile then the value of American call option increases. Finally in fig. 5(d). when the maturity time is high then the option price is also high. So we can establish our opinion without any doubt that if our expiration time is high then it is obvious, the call option price is also high.

\section{CONCLUSION}

In this paper we have discussed four effective option pricing methods, As the methods for put option pricing and call option pricing is almost same, we have discussed here only call option pricing here, we have used the market data and used historical volatility as the market volatility. All of the four methods give almost the same results, but we have noticed that the Monte Carlo simulation gives us best results when we use more simulations. We have also seen that by Monte Carlo simulation and Black Scholes model, we only price the European options, but with the binomial and trinomial method, we can value both the European and American type options and each case they give almost the same results.

\section{REFERENCES}

[1] H. Xiaoping, G. Jiafeng, D. Tao, C. Lihua and C. Jie, "Pricing Options Based on Trinomial Markov Tree," Discrete Dynamics in Nature and Society, pp. 1-7, 16 July 2014.

[2] Shi, X., Zhang, L., \& Kim, Y. S. (2016). A markov chain approximation for American option pricing in tempered stablegarch models. Frontiers in Applied Mathematics and Statistics, 1,13 .

[3] J. C. Hull, OPTIONS, FUTURES, And Other Derivatives, United States of America: Pearson, 2015, 2012.

[4] S. E. Shreve., Stochastic calculus for finance. I: The binomial asset pricing model. New York: Springer., 2004.

[5] P. Wilmott, S. Howison, and J. Dewynne. The mathematics of financial derivatives. A student introduction. S. E. Shreve. Stochastic calculus for finance. II: Continuous-time models. New York: Springer., 2004.

[6] H. Föllmer and A. Schied., Stochastic finance. An introduction in discrete time. Berlin: de Gruyter., 2004.

[7] Yeh, I. C., \& Lien, C. H. (2020). Evaluating real estate development project with Monte Carlo based binomial options pricing model. Applied Economics Letters, 27(4), 307-324.

[8] S. E. Shreve., Stochastic calculus for finance. II: Continuoustime models. New York: Springer., 2004.

[9] J. M. Steele., Stochastic calculus and financial applications. New York: Springer., 2001

[10] T. Björk., Arbitrage theory in continuous time. 2nd ed. Oxford: Oxford University Press., 2004.

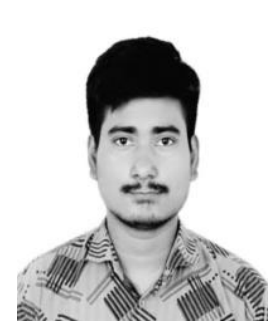

Sujon Chandra Sutradhar was born at Dohar in Dhaka in the year 1996. He has completed his B.SC degree in Applied Mathematics from the University of Dhaka in 2018. Currently, he is a research student and doing his research in the field of Financial Mathematics. Besides, he is a running student of M.SC in Applied Mathematics, University of Dhaka.

His interest includes Stochastic modelling in finance, Time series analysis, Machine learning, Data analysis and its related field. Now he is doing his thesis on the topic of Real Option analysis with changing volatility.

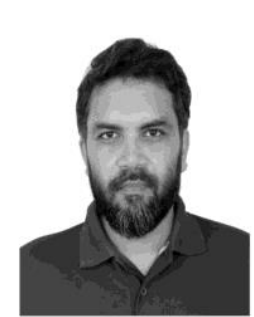

A B M Shahadat Hossain is an Associate Professor in the department of Applied Mathematics at the University of Dhaka, Dhaka-1000, Bangladesh. $\mathrm{He}$ received his Ph.D. degree in 2012 on Probability and Statistics and MS on Mathematical Finance from The University of Manchester, UK in 2008. He also completed M.Sc. and B.Sc. (Hons) from the University of Dhaka in 1999 and 2001, respectively. After completing M.Sc., he joined Independent University, Bangladesh (IUB) in 2001 as a junior lecturer and joined the University of Dhaka as a lecturer in April 5, 2003. Currently, he is teaching three important courses, namely, Introduction to Financial Mathematics, Stochastic Calculus in Undergraduate level and Stochastic Modeling in Finance in Graduate level. He introduced these courses first time at Dhaka University in 2014. He is also the founding Director of CMDA (Center for Mathematics Development Alternative), Dhaka, Bangladesh.

He has published 18 research papers in reputed national and international journals. He is the Director, IQAC of the department of Applied Mathematics, DU. His research interest in Mathematical Finance, Financial Econometrics, Time series Analysis (Bayesian) and Forecasting in Finance, Dynamical Systems, Mathematical Biology etc. He supervised 11 MS students and 21 Fourth year honors students. Presently, he is supervising $2 \mathrm{MS}$ students and 3 honors students. 